\title{
Adsorption of Amino Acids, Aspartic Acid and Lysine onto Iron-Oxide Nanoparticles
}

\author{
Klementina Pušnik, Mojca Peterlin, Irena Kralj Cigić, Gregor Marolt, Ksenija Kogej, Alenka \\ Mertelj, Sašo Gyergyek, Darko Makovec*
}

\section{Chemicals used for Synthesis of the Nanoparticles}

Iron (III) sulphate hydrate (97\%, reagent grade), iron (II) sulphate heptahydrate (ACS, 99\%), DLaspartic acid (98\%), DL-lysine monohydrate (98\%), sodium hydroxide (98\%), ammonium hydroxide $\left(\mathrm{NH}_{4} \mathrm{OH}\right)(\mathrm{aq})(25 \%)$, and phosphate-buffered saline (PBS) were purchased from Alfa Aesar.

\section{Synthesis of Iron-Oxide Nanoparticles}

The magnetic iron-oxide nanoparticles were precipitated from an aqueous solution of $\mathrm{FeSO}_{4}(0.027$ $\mathrm{mol} / \mathrm{L})$ and $\mathrm{Fe}_{2}\left(\mathrm{SO}_{4}\right)_{3}(0.0115 \mathrm{~mol} / \mathrm{L})$ using a concentrated ammonia solution $(25 \%)$. The $\mathrm{pH}$ value of the solution was suddenly increased to 11.6 by the addition of ammonia under vigorous mixing. After an ageing time of $30 \mathrm{~min}$ the iron-oxide particles were magnetically separated and washed several times using a diluted ammonia solution with a high $\mathrm{pH}$ of 10.5 to provide a high, negative surface charge on the nanoparticles (see the changing of the zeta-potential with $\mathrm{pH}$, presented in Figure 3), thus preventing any strong agglomeration during their washing.

\section{XRD of Synthesized Iron-Oxide Nanoparticles}

For X-ray diffractometry (XRD) analysis the suspension of thoroughly washed, as-synthesized nanoparticles was lyophilized. The XRD spectra were recorded using a PANalytical X` Pert PRO. The average nanoparticle size (the mean size of the coherently scattering crystal region) was obtained from refinements of the XRD spectra $\left(2 \theta=20^{\circ}-60^{\circ}\right)$ using the method based on Scherrer equation. ${ }^{1}$ The Xray powder line-profile was fitted using the crystallographic program Topas2R 2000 from Bruker AXS. Fitting of the line-profile was based on a convolution approach (Pawley method) ${ }^{2}$ in which the line shape is composed of the $\mathrm{Cu}-\mathrm{K} \alpha$ emission profile, the dimensions of the diffractometer and the physical variables of the sample. ${ }^{3}$ 


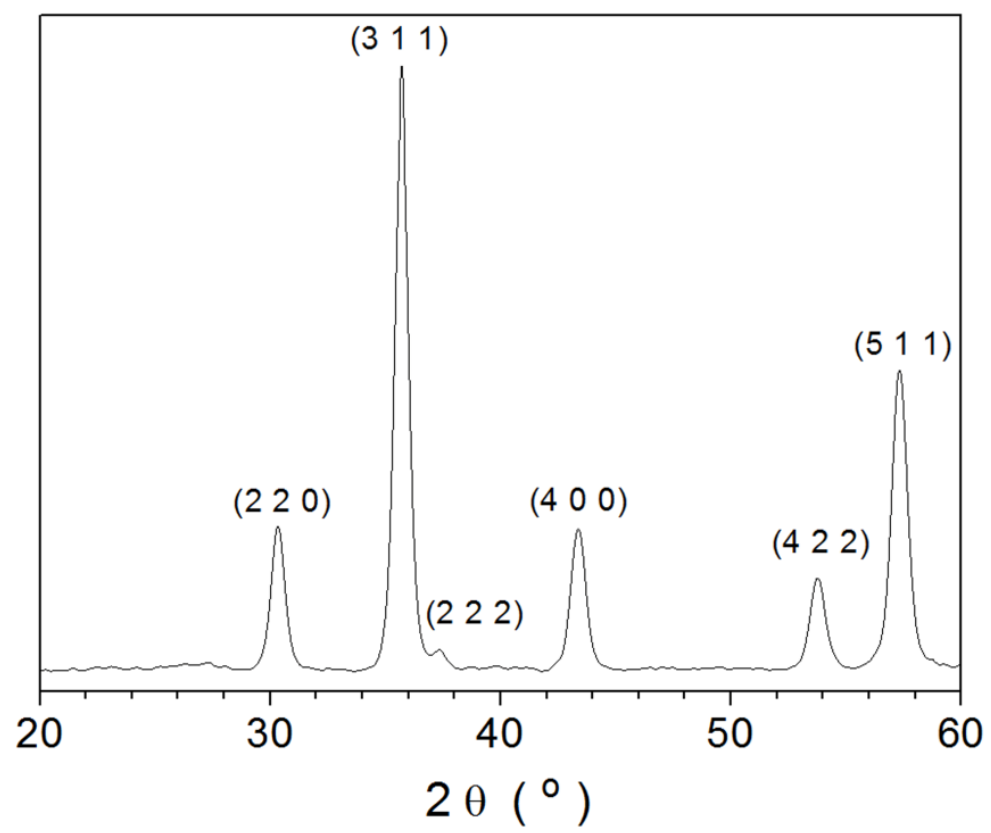

Figure S1. XRD spectrum of iron-oxide nanoparticles. The reflections ware indexed according to the spinel structure.

\section{Raman Spectroscopy of Synthesized Iron-Oxide Nanoparticles}

Phase composition of the as-synthesized nanoparticles was checked using Raman spectroscopy (Horiba Yvon Lab RAM spectrometer). The sample was prepared with lyophilization of the suspension of thoroughly washed, as-synthesized nanoparticles. The laser excitation source was the $632.8 \mathrm{~nm}$ line from a He-Ne laser with a power of $1.5 \mathrm{~mW}$.

Raman spectrum (Figure S2) of the dried nanoparticles shows Raman signals as broad features at 379 $\mathrm{cm}^{-1}, 485 \mathrm{~cm}^{-1}$ and a asymmetric feature centered at approx. $690 \mathrm{~cm}^{-1}$. It is reasonable to assume that the asymmetric feature is composed of two components centered at $670 \mathrm{~cm}^{-1}$ and $718 \mathrm{~cm}^{-1}$. The spectrum showing such features is characteristic of maghemite $\left(\gamma-\mathrm{Fe}_{2} \mathrm{O}_{3}\right){ }^{4}$ 


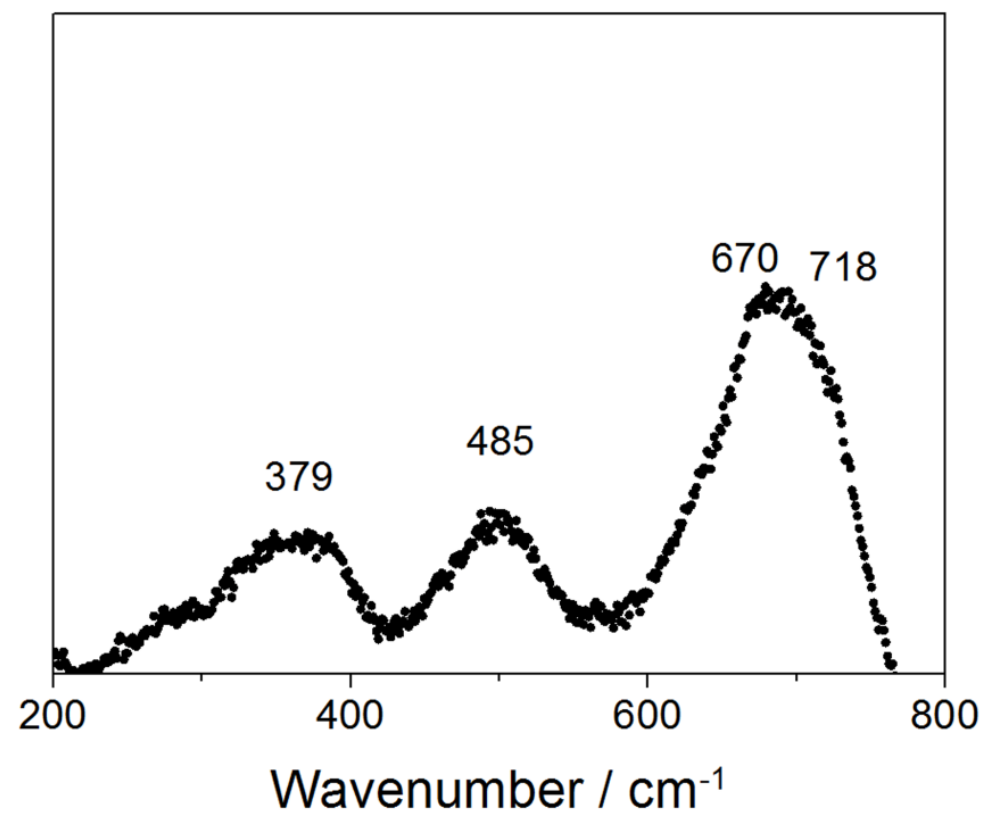

Figure S2. Raman spectrum of as-synthesized iron-oxide nanoparticles.

\section{Magnetic Properties of Synthesized Iron-Oxide Nanoparticles}

For measurements of the magnetic properties the suspension of thoroughly washed, as-synthesized nanoparticles was lyophilized. The magnetic properties of the nanoparticles were measured at room temperature using a Lake Shore 7307 VSM vibrating-sample magnetometer.

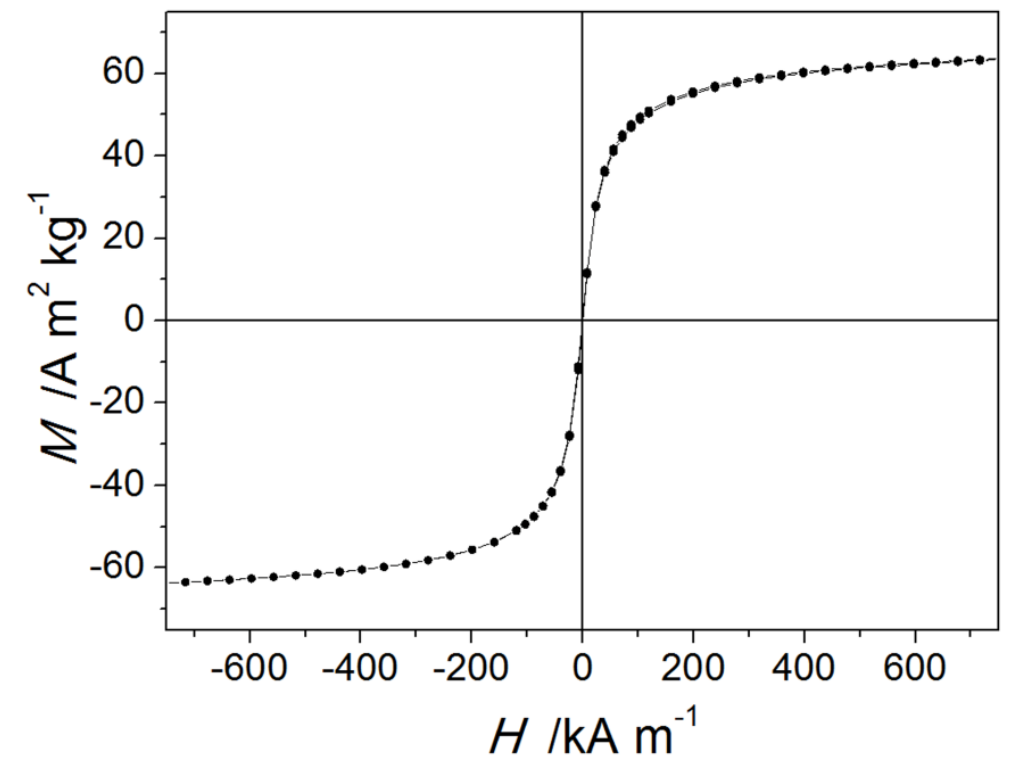

Figure S3. Room-temperature magnetic hysteresis of synthesized iron-oxide nanoparticles. 


\section{Simultaneous Adsorption of Two Amino Acids}

Nanoparticles in the aqueous medium were equilibrated with aspartic acid (Asp), lysine (Lys), and their equimolar mixture at different $\mathrm{pH}$ values of the suspension. The total concentration of amino acids in the suspension was $3.2 \mathrm{mg} / \mathrm{mL}$ (AA/SPION mass ratio = 1.44). Then, the suspensions were ultra-centrifuged to sediment the nanoparticles and the supernatants were analyzed using HPLC (Table S1).

Table S1. AA content in the supernatant of the SPION suspensions equilibrated with Asp, Lys and their mixture.

\begin{tabular}{|c|c|c|c|c|c|}
\hline \multirow[t]{2}{*}{ AA } & \multicolumn{2}{|c|}{ AA conc. in suspension } & \multirow{2}{*}{$\begin{array}{l}\mathrm{pH} \\
{[/]}\end{array}$} & \multicolumn{2}{|c|}{ AA conc. in supernatant } \\
\hline & $\operatorname{Asp}\left[g^{-1}\right]$ & Lys $\left[\mathrm{g} \mathrm{L}^{-1}\right]$ & & Asp $\left[\mathrm{g} \mathrm{L}^{-1}\right]$ & Lys $\left[\mathrm{g} \mathrm{L}^{-1}\right]$ \\
\hline Asp & 3.2 & l & & 2.1 & l \\
\hline Lys & 1 & 3.2 & 4 & I & 3.0 \\
\hline Asp + Lys & 1.5 & 1.7 & & 1.1 & 1.0 \\
\hline Asp & 3.2 & 1 & & 2.1 & I \\
\hline Lys & I & 3.2 & 7 & I & 2.9 \\
\hline Asp + Lys & 1.5 & 1.7 & & 1.4 & 1.3 \\
\hline Asp & 3.2 & I & & 2.5 & I \\
\hline Lys & & 3.2 & 11 & I & 3.1 \\
\hline Asp + Lys & 1.5 & 1.7 & & 1.1 & 1.1 \\
\hline
\end{tabular}

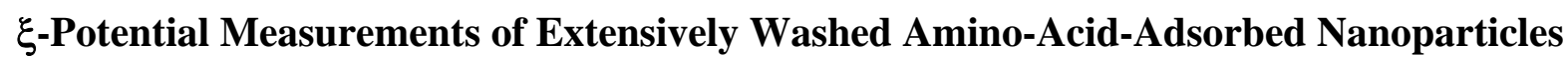

After adsorption of the AAs, the nanoparticles were washed with different amounts of distilled water.

$0.1 \mathrm{~g}$ of the nanoparticles was dispersed in $45 \mathrm{~mL}$ water, the AA was added in a mass ratio AA/SPION $=1.44$ and the $\mathrm{pH}$ was set to $\mathrm{pH}=2$. After a longer time allowed for the adsorption, the $\mathrm{pH}$ of the suspension was increased to 7 using diluted ammonia. For washing, the separated nanoparticles were re-dispersed in $45 \mathrm{~mL}$ of distilled water, while the $\mathrm{pH}$ was maintained at 7 . The sedimentation/redispersion cycle was repeated 30 times.

Figure S4 shows the $\xi$-potential as a function of $\mathrm{pH}$ for the both AAs. The AA-adsorbed nanoparticles were washed with three repeating washing cycles and with 30 washing cycles.

In the case of Asp, the IEP slightly increased with the washing compared to the IEP of the assynthesized nanoparticles (without the AA). The result suggests that after washing the Asp is mainly adsorbed in the form of a single molecular layer. The increase in the IEP is in accordance with the bonding of the Asp with the both carboxyl groups onto the nanoparticle surfaces and the amino group 
oriented outwards. Even very intensive washing ( 30 washing cycles) did not wash all the AAs from the surface, as the IEP remains different than the IEP for the as-synthesized nanoparticles.
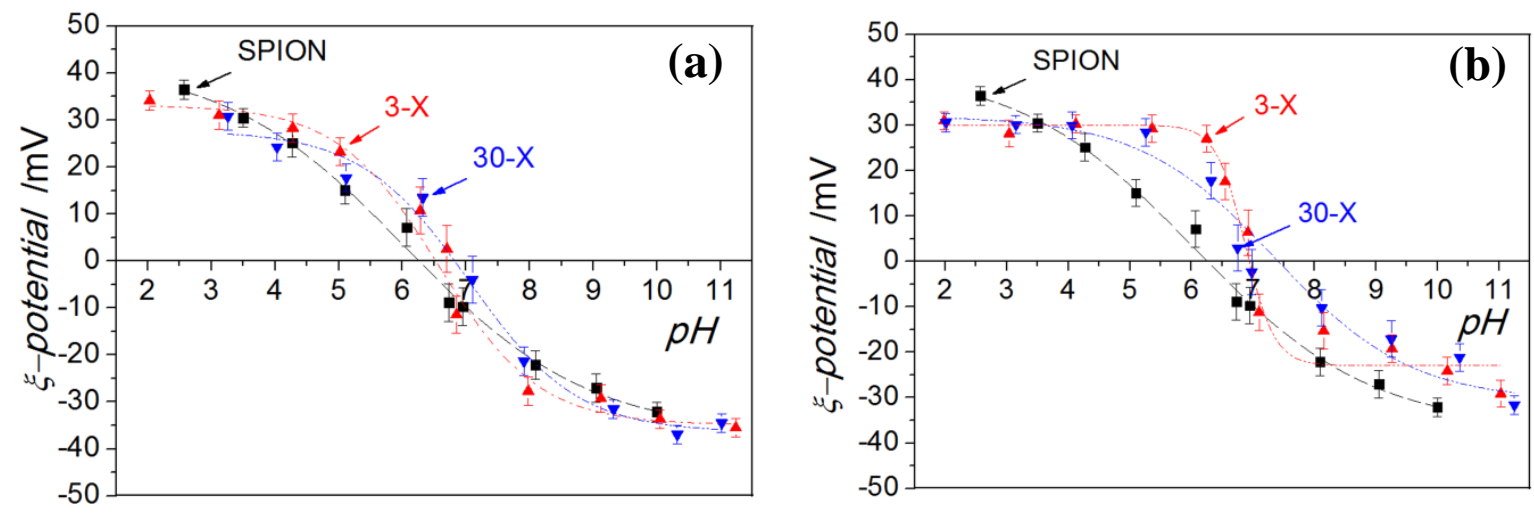

Figure S4. $\xi$-potential as a function of $\mathrm{pH}$ for Asp-adsorbed (a) and Lys-adsorbed (b) nanoparticles. The nanoparticles were washed with three repeating washing cycles (3-X) and with 30 washing cycles $(30-X)$.

\section{Osmolality Measurement}

The osmolality of the amino acid solutions and suspensions was determined based on measurements of the freezing-point depressions using a Knauer osmometer. The instrument was calibrated using aqueous $\mathrm{KCl}$ solutions of known osmolalities $\left(0.02-0.10 \mathrm{osm} \mathrm{L}^{-1}\right)$. The osmolality of the $\mathrm{KCl}$ was calculated by taking into account the complete ionization of $\mathrm{KCl}$ in water. Figure $\mathrm{S} 5$ shows an example of the calibration line.

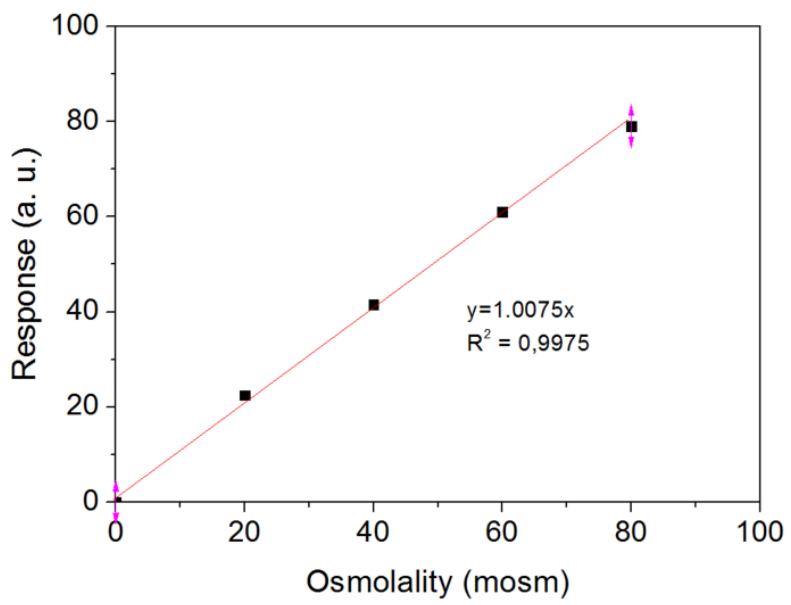

Figure S5. Calibration line for the measurement of osmolality using a Knauer osmometer obtained with $\mathrm{KCl}$. 


\section{DLS Measurements of Hydrodynamic Size of Molecular Associates in the Amino-Acid}

\section{Aqueous Solutions}

The size of the molecular associates in the AA solutions was followed using DLS. The measurements were performed at different scattering angles: $90^{\circ}, 30^{\circ}$, and $15^{\circ}$. However, at the angle $90^{\circ}$ the $\mathrm{S} / \mathrm{N}$ ratio was too low, at $15^{\circ}$ in some cases the scattering from larger entities (which is stronger in the forward direction) screened the scattering from smaller ones, so we focused on measurements at the scattering angle $30^{\circ}$. Each sample was measured at least two times, and the duration of each measurement was $24 \mathrm{~h}$.

Figures S6-S9 show the number-weighted distribution of the hydrodynamic diameters of the particles in the aqueous solutions of the both $\mathrm{AAs}(3 \mathrm{mg} / \mathrm{mL})$ at $\mathrm{pH}=3$ and $\mathrm{pH}=11$. The graphs on the left show narrow peaks at small diameters and the graphs on the right much smaller, but broader peaks at larger diameters.
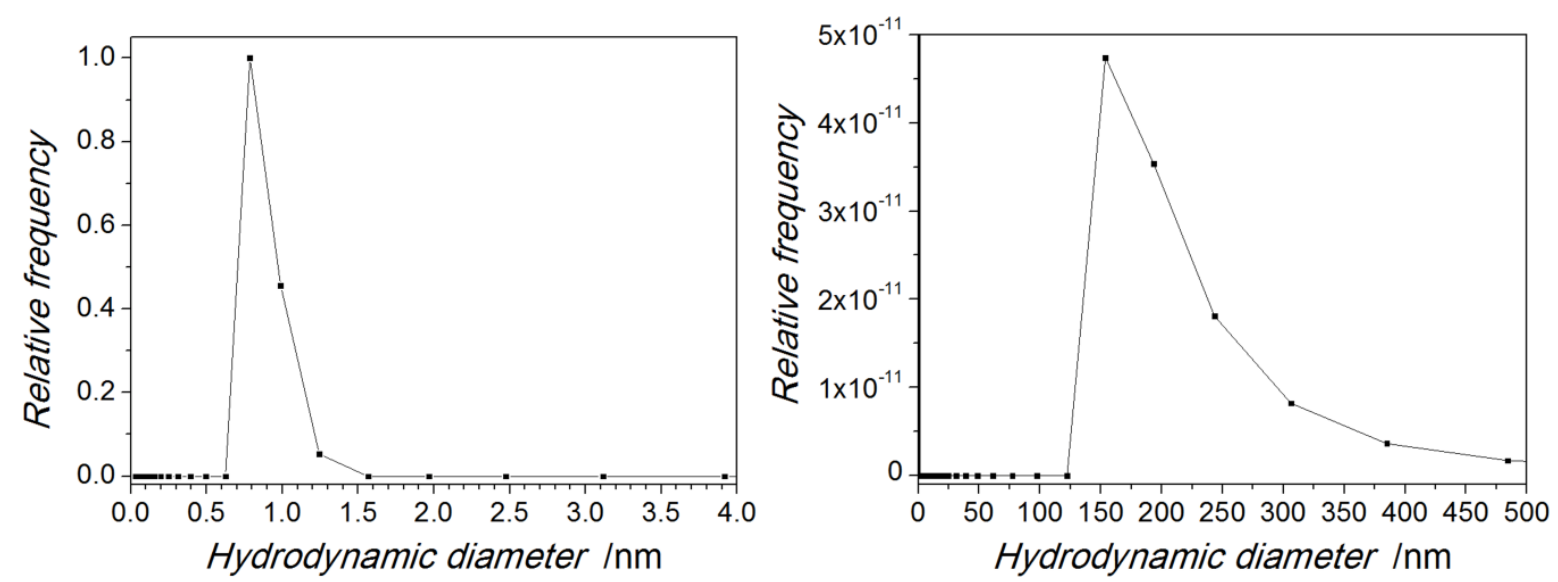

Figure S6. Number-weighted empirical distribution of the hydrodynamic diameters of the particles in Asp aqueous solution $(3 \mathrm{mg} / \mathrm{mL})$ at $\mathrm{pH}=3$.
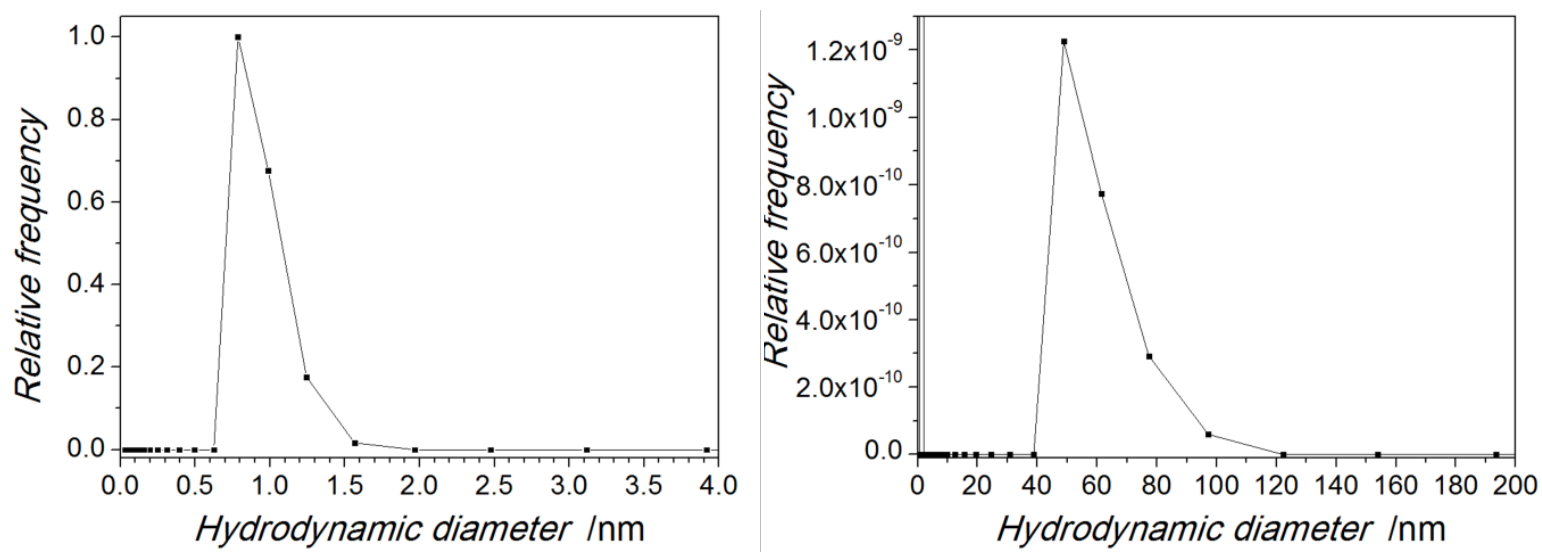

Figure S7. Number-weighted empirical distribution of the hydrodynamic diameters of the particles in Asp aqueous solution $(3 \mathrm{mg} / \mathrm{mL})$ at $\mathrm{pH}=11$. 

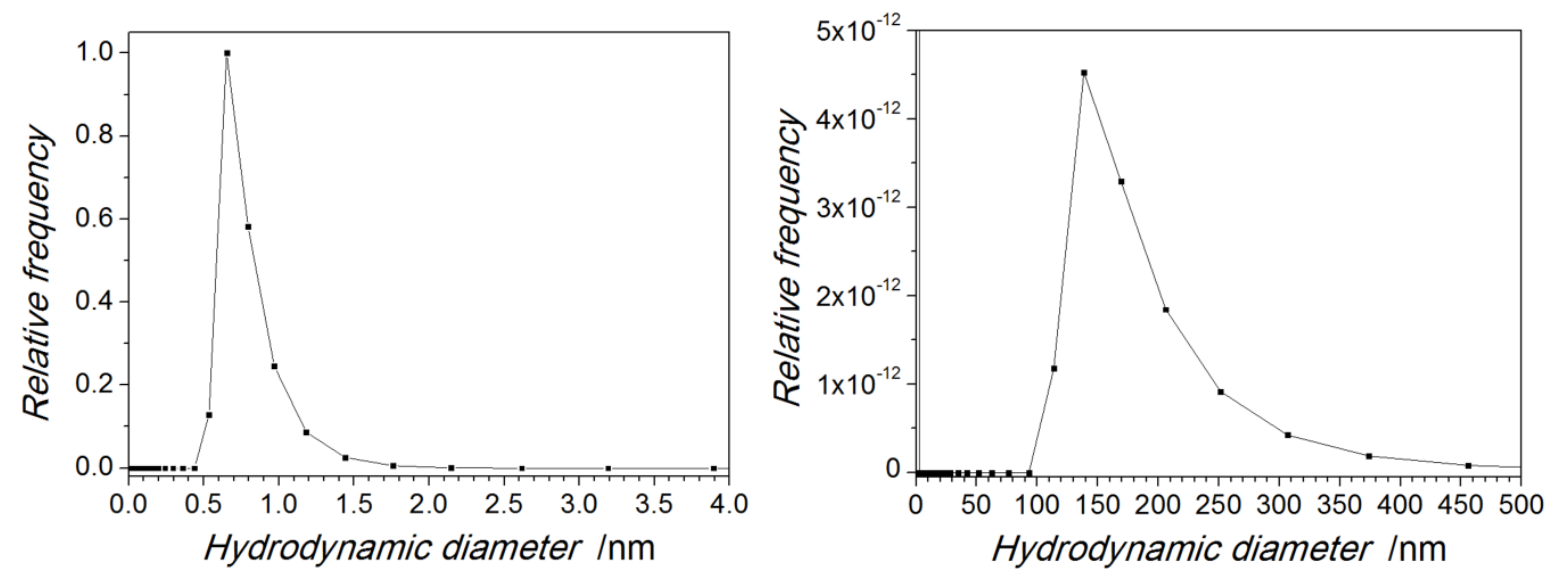

Figure S8. Number-weighted empirical distribution of the hydrodynamic diameters of the particles in Lys aqueous solution $(3 \mathrm{mg} / \mathrm{mL})$ at $\mathrm{pH}=3$.
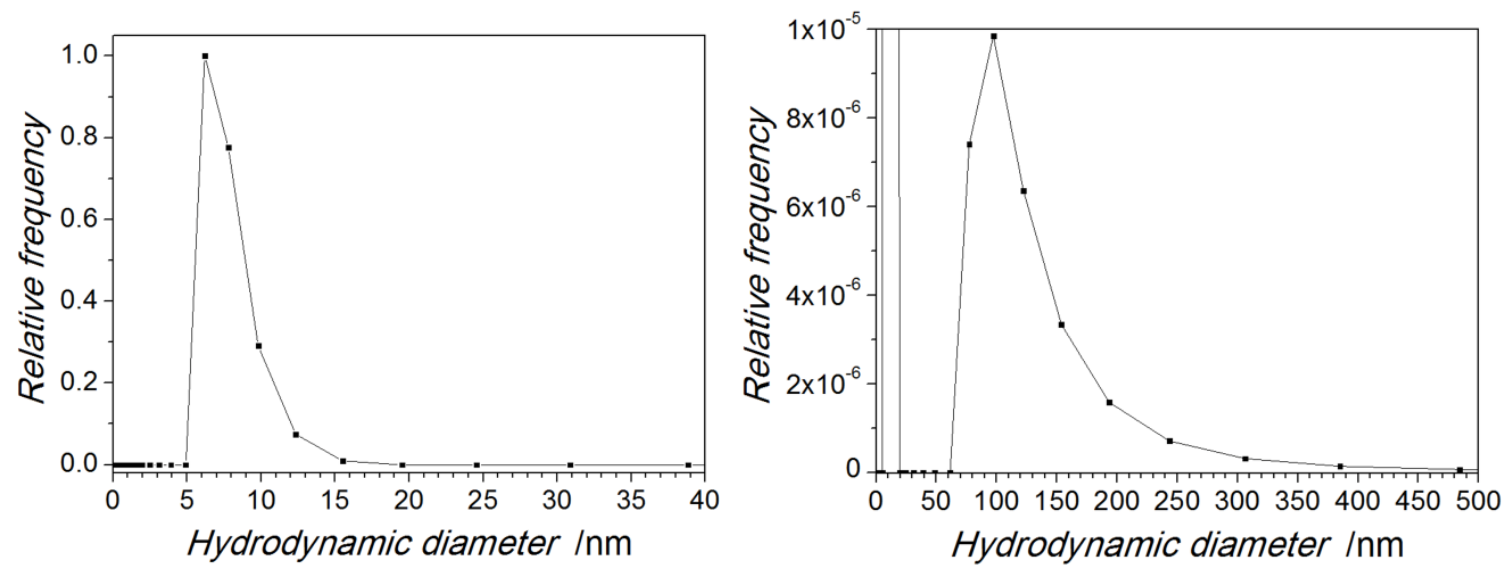

Figure S9. Number-weighted empirical distribution of the hydrodynamic diameters of the particles in Lys aqueous solution $(3 \mathrm{mg} / \mathrm{mL})$ at $\mathrm{pH}=11$.

\section{Chemicals used for HPLC Synthesis}

Amino acid internal standard DL-norvaline (99\%), derivatization reagent 3-MPA/OPA (3-mercapto propionic acid/o-phthaldehyde, $99 \%$ ) and solvents for mobile phase: acetonitrile (99.9\%), methanol (99.9\%) were purchased from Sigma Aldrich. The water used for the dilutions and for the mobile phase was purified with a Mili-Q water-purification system (Millipore, ZDA). The sodium acetate (95.5 \%) was from Kemika; the boric acid (99.5\%) was from Fluka; the potassium chloride (99 \%) was from Fisher Scientific; and the sodium hydroxide (97\%), hydrochloric acid (32\%) and acetic acid (99.8\%) were from Sigma Aldrich. 


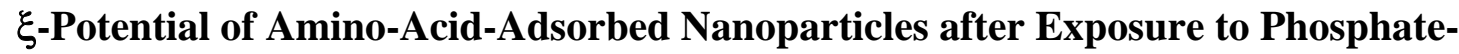 Buffered Saline}

Stable suspensions of AA-adsorbed nanoparticles were prepared as explained in the section Materials and Methods. The nanoparticles were sedimented using ultracentrifugation and re-dispersed in phosphate-buffered saline (PBS) at a concentration of $2 \mathrm{mg} / \mathrm{mL}$. The suspension was mixed overnight. Then, the nanoparticles were sedimented again and re-dispersed in distilled water $(\sim 0.4 \mathrm{mg} / \mathrm{mL})$. The $\xi$-potential of the suspension was measured as a function of the $\mathrm{pH}$ using Brookhaven Instruments Corporation, Zeta PALS instrument, maintaining the $\mathrm{pH}$ of the original suspension.

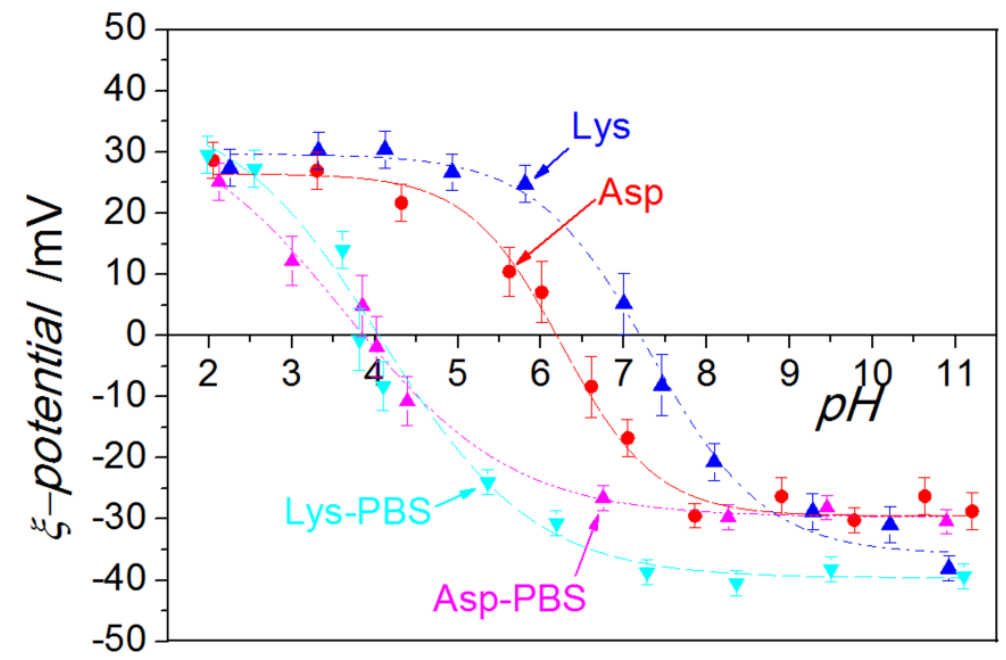

Figure S10. $\xi$-potential as a function of $\mathrm{pH}$ for AA-adsorbed SPIONs before (Asp, Lys) and after they were exposed to PBS (Asp-PBS, Lys-PBS).

\section{Literature}

(1) Cullity, B.D. Elements of X-ray Diffraction, Addison-Wesley: Reading, 1987.

(2) Pawley, G. S. Unit-Cell Refinement from Powder Diffraction Scans. J. Appl. Cryst. 1981, 14, 357-365.

(3) Cheary, R. W.; Coelho, A. A Fundamental Parameters Approach to X-ray Line-Profile Fitting. J. Appl. Cryst. 1992, 25, 109-121.

(4) Cornell, R.M.; Schwertmann, U. The Iron Oxides; Structure, Properties, Reactions, Occurrences and Uses, Wiley-VCH: Weinheim, 2003. 